\title{
Looking back to look forward
}

$\mathrm{P}$ lastic surgery has a fascinating history, which is really the history of ideas. It is the history of how we are connected and how we are alike; how we learn from each other and share ideas. It is the story of similarities and differences, and of fascinating leaps of faith and connections.

The story of Indian rhinoplasty and how it was introduced in the west from India, where it had been practised for millennia, is well known. Gaspare Tagliacozzi, Surgeon of Bologna, developed arm flaps for nasal reconstruction, and published De curtorum chirurgia per insitionem in 1597 (1), showing, in great detail, how to do his operation. Notably, he advised surgeons to make sure to give the patient hope.

Harold Gillies and Fulton Risdon used many tubed pedicle flaps for facial reconstruction in Sidcup, England during World War I. The tubing was an idea to train the blood supply longitudinally and to bring new soft tissue into a deficient region. Gillies was about to publish this idea when he discovered that Filatov had already published it. It seems to me that publishing this idea was not so much a competition as a connection, an idea that would occur to similar minds unable to directly communicate due to separation by distance. Nowadays, these ideas would be shared quickly with modern electronic communication.

The pedicle idea is even older than that. Celsus, a Roman physician, was closing lower leg defects 2000 years ago using one or two vertical flap(s) that he slid laterally into the defect. Tubing and distantly moving the flap was only an inspiration away even then. Look closely at Tagliacozzi's arm flap diagram (1597). Does the pedicle look tubed to you? Did it start to tube itself over a three-week period? This is an interesting puzzle for the amateur surgical sleuth.

Today, we tend to think that various operations could not have been performed due to the lack of anaesthesia or instruments. I think it is likely that surgeons had these things, but they went undescribed.

The tube pedicle came into its own again to treat severe burn deformities during World War II (2). Reconstruction was slow and took many operations, but the results were outstanding. I have seen some patient's results many decades after surgery and I wonder if such good results could be achieved by surgery today. Unfortunately, some surgeons did not write much, and some of what was learned is now lost, particularly

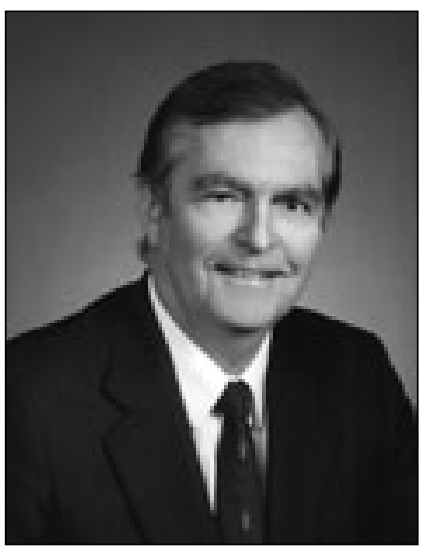

John R Taylor the detail of timing, flap insetting and flap defatting. On the other hand, perhaps we do know. These master surgeons advised us not to rush, to follow the basic principles of healing and take the long view. Perhaps they thought written detail was for the poorly trained. They advised us to learn the principles and all things would become clear to us. Watch, wait and learn was what they taught, and, above all, control impatience.

Hence, the importance of saving things: charts, photographs, notes, books and papers. All these are of interest to a historian, indeed, any plastic surgeon interested in studying the progression of ideas.

I have a book entitled Plastic and Cosmetic Surgery by Frederick Strange Kolle, MD, of New York, published in 1911 (3). In this book, he describes the state of the art, including local anaesthesia, paraffin for augmentation and an extensive study, with diagrams, of reconstructive operations of all kinds, including otoplasty and rhinoplasty. The interesting thing about this book is that it shows his mind a mind very similar to a plastic surgeon today, working on the same problems we do; a man eager to share what he knew in detail, not at all worried about competition.

Dr Kolle is now little known, and I suspect he would not have cared. It is the fate of all of us, I suspect; the prize is the chase, and fame is fleeting. The excitement is the problem to 
be solved. If there is a lesson to be learned, I suppose it is that it is much more exciting to share problems with surgeons that we respect and admire; our colleagues, rather than to work in isolation and secrecy. It is better to be outgoing and not inward looking. It is good to admire someone else's abilities rather than to be protective. This can be learned from the archives and history of the plastic surgery Greats.

We need to collect and protect our archives of plastic surgery. Everything is of value to a collector - old letters, charts, medical records and old books. Old photographs and patient lists, diagrams of operations and published papers are all valuable. These are the records of plastic surgery thoughts, and ideas tried, used, abandoned and rediscovered.
Most of our history is the record of surgeons trying to solve the problems of healing, repairing and rebuilding.

The problems never go away; what changes are the ways we try to solve them.

$$
\begin{array}{r}
\text { John R Taylor } \\
\text { Archivist } \\
\text { Canadian Society of Plastic Surgeons } \\
\text { E-mail jrtaylor@ca.inter.net }
\end{array}
$$

\section{REFERENCES}

1. Gnudi MT, Webster JP. The Life and Times of Gaspare Tagliacozzi. New York: Herbert Reichner,1951:183.

2. Gillies H, Millard DR.The Principles and Art of Plastic Surgery, Vol 1. Boston: Little Brown and Company, Boston, 1957.

3. Kolle FS. Plastic and Cosmetic Surgery. New York and London: D Appleton and Company, 1911:2. 